\title{
Epigallocatechin-3-gallate inhibits migration and invasion of human renal carcinoma cells by downregulating matrix metalloproteinase-2 and matrix metalloproteinase-9
}

\author{
SHAO-JUN CHEN, XU-DONG YAO, BO PENG, YUN-FEI XU, GUANG-CHUN WANG, \\ JIANHUA HUANG, MIN LIU and JUN-HUA ZHENG \\ Department of Urology, Shanghai Tenth People's Hospital, Tongji University, Shanghai 200072, P.R. China
}

Received November 27, 2014; Accepted January 11, 2016

DOI: 10.3892/etm.2016.3050

\begin{abstract}
Theanticancerpropertiesofepigallocatechin-3-gallate (EGCG) are documented in the treatment of several types of cancer; however, there is no relevant evidence for its efficacy in the treatment of renal cell carcinoma (RCC). In the present study, the therapeutic effects of EGCG in vitro were investigated, with particular attention to the metastatic behavior of human RCC cells. MTT assays and flow cytometry were performed to detect the effects of EGCG on the proliferation and apoptosis of RCC cells. The migration and invasion abilities of RCC cells following treatment with EGCG were assessed by wound-healing and Transwell assays, respectively. Gelatin zymography and western blot analysis were performed to analyze the effect of EGCG on matrix metalloproteinase-2 (MMP-2) and MMP-9 expression levels. The results suggested that EGCG was able to inhibit the proliferation of RCC cells, induce apoptosis and effectively suppressed the migration and invasion of RCC cells. In addition, EGCG treatment resulted in the downregulation of MMP-2 and MMP-9 in RCC cells. We hypothesize that the anticancer effect associated with EGCG may involve the downregulation of MMP-2 and MMP-9. The present results suggest the potential of EGCG as a novel therapeutic agent against RCC.
\end{abstract}

\section{Introduction}

Renal cell carcinoma (RCC) is a frequently observed malignant neoplasm in the urinary system and is the 6th leading cause of cancer deaths in Western countries. Each year, 200,000 patients are diagnosed with the malignancy,

Correspondence to: Dr Min Liu or Dr Jun-Hua Zheng, Department of Urology, Shanghai Tenth People's Hospital, Tongji University, 301 Yanchang Road, Shanghai 200072, P.R. China

E-mail: kidneyliu@163.com

E-mail: zhengjh0471@sina.com

Key words: epigallocatechin-3-gallate, renal cell carcinoma, migration, invasion, matrix metalloproteinase-2, matrix metalloproteinase- 9 resulting in $\sim 100,000$ deaths, and its incidence has increased in recent years $(1,2)$. There is no specific tumor marker for $\mathrm{RCC}$ and RCC is resistant to chemotherapy and radiotherapy; thus, surgical resection remains the most effective treatment for localized primary RCC. However, $\sim 30 \%$ of RCC cases develop into metastatic disease following nephrectomy, and the median survival period is 13 months $(3,4)$. Metastasis remains a significant challenge for urologists and novel prophylactic/therapeutic agents against metastasis are required (5).

Tumor metastasis is a complex process and an important step involved in the process is the degradation of the basement membrane (BM) and extracellular matrix (ECM), the latter being the mechanical barrier that serves to prevent cell invasion in tissues (6). Matrix metalloproteinases (MMPs) are a family of neutral proteinases that digest the primary $\mathrm{BM}$ and ECM components that are overexpressed in almost all human cancers $(7,8)$. Among the members of the MMP family, MMP-2 (72 kDa type IV collagenase gelatinase A) and MMP-9 (92 kDa type IV collagenase gelatinase B) have the ability to degrade collagen, a major component of the basement membrane, and are strongly associated with tumor invasion and metastasis (9). It is thus indicated that the inhibition of MMPs, in particular MMP-2 and MMP-9, may be a therapeutic strategy.

Epigallocatechin-3-gallate (EGCG; chemical structure displayed in Fig. 1A) is a stable water-soluble flavonoid that is the most abundant catechin in green tea (10). A previous study suggested that consumption of green tea may reduce the risk of cancers including those of the stomach, colon, lung, liver, rectum, breast and pancreas (11). EGCG exerts its anticancer effects via the modulation of processes of cellular differentiation, proliferation, apoptosis, angiogenesis and metastasis (12). The inhibitory effect of EGCG on MMP-2 and MMP-9 expression levels has been reported in a number of cancer cell lines (13). In addition, EGCG may inhibit the metastasis of hypopharyngeal, prostate and pancreatic cancers by downregulating MMPs (14-16). However, the effect of EGCG on RCC cells has yet to be elucidated.

The aim of the present study was to evaluate the effect of EGCG on RCC cell migration and invasion in vitro. MTT assays and flow cytometry were performed to evaluate the 
effect of EGCG on RCC cell viability and wound-healing, and transwell invasion assays were employed to examine the effect of EGCG on RCC cells. Finally, the effect of EGCG on metastasis-related MMP-2 and MMP-9 expression levels was evaluated using gelatin zymography and western blot analysis.

\section{Materials and methods}

Cell culture. The RCC cell lines 786-0 and ACHN were purchased from Cell Bank of Type Culture Collection of Chinese Academy of Sciences (Shanghai, China), were cultured in RPMI-1640 (Sigma-Aldrich, St. Louis, MO, USA) supplemented with $10 \%$ fetal bovine serum (FBS; Gibco; Thermo Fisher Scientific, Inc., Waltham, MA, USA) and 1\% antibiotics $(100,000 \mathrm{U} / 1$ penicillin and $100 \mathrm{mg} / 1$ streptomycin; Thermo Fisher Scientific, Inc.). Cells were cultured at $37^{\circ} \mathrm{C}$ in a humidified atmosphere containing $5 \% \mathrm{CO}_{2}$. Cells of the exponential phase of growth were used in the subsequent experiments.

Cell proliferation assay. The effect of EGCG on RCC cell proliferation was measured by MTT assay. Cell lines 786-O and ACHN were plated into 96-well plates at a density of $2 \times 10^{4}$ cells/well in RPMI 1640 culture medium and incubated at $37^{\circ} \mathrm{C}$ for $24 \mathrm{~h}$. Subsequent to treatment with EGCG (Sigma-Aldrich) at various concentrations $(0,5,10,20$, 40 and $60 \mu \mathrm{g} / \mathrm{ml}$ ) for 12,24 and $48 \mathrm{~h}$, the cells were incubated with $20 \mu 1$ MTT $\left(5 \mathrm{mg} / \mathrm{ml}\right.$; Sigma-Aldrich) at $37^{\circ} \mathrm{C}$ for $4 \mathrm{~h}$. Following this, the medium was removed and $150 \mu \mathrm{l}$ dimethyl sulfoxide (Sigma-Aldrich) was added to each well for $10 \mathrm{~min}$ at room temperature to solubilize the crystals. Finally, cell proliferation was determined by absorbance measurements at $490 \mathrm{~nm}$ on a Model 680 microplate reader (Bio-Rad Laboratories, Inc., Hercules, CA, USA). Cell viability was expressed as a percentage of the absorbance obtained for the control group. A minimum of three independent experiments were performed.

Flow cytometry. The proapoptotic effect of EGCG on RCC cells was evaluated using an FITC Annexin V Apoptosis detection kit (BD Pharmingen, San Diego, CA, USA) and quantified using flow cytometry. Briefly, cells $\left(1 \times 10^{6}\right)$ were plated into six-well plates and incubated overnight at $37^{\circ} \mathrm{C}$, then treated with EGCG at $0,10,20$ or $40 \mu \mathrm{g} / \mathrm{ml}$ for $24 \mathrm{~h}$. Following centrifugation ( $326 \mathrm{x} \mathrm{g}$ ) for $5 \mathrm{~min}$ at room temperature, the harvested cells $\left(1 \times 10^{6}\right)$ were washed twice with cold phosphate-buffered saline (PBS) and immediately resuspended in the physiological buffer (1X) provided within the kit. Cells were then maintained in the dark for $15 \mathrm{~min}$ at room temperature with $5 \mu \mathrm{l}$ of both propidium iodide and fluorescein isothiocyanate conjugated annexin $\mathrm{V}$, after which the samples were analyzed immediately using a FACSCalibur flow cytometer (BD Biosciences, San Jose, CA, USA). The results were quantified using BD CellQuest 5.1 software (BD Biosciences). Apoptosis rates were expressed as percentages of early and late apoptosis cells. The experiments were repeated three times.

Wound-healing assay. In vitro cell migration was assessed using a scratch wound assay. Cell lines 786-O and ACHN were seeded into a 6-well plate and cultured in complete medium to $80 \%$ confluency. Following serum starvation for $24 \mathrm{~h}$, the cell monolayers were carefully wounded using a pipette tip and washed with PBS to remove floating cells. Wounded monolayers were then incubated in media containing various concentrations of EGCG at $37^{\circ} \mathrm{C}$ with $5 \% \mathrm{CO}_{2}$ for $24 \mathrm{~h}$. Cells migrating into the wound area were observed and counted under an inverted microscope (SKZ1047; SKZ Industrial Co., Ltd., Shandong, China). Results were displayed as percentages of cells migrated compared with those in the control group. All experiments were performed in triplicate.

Transwell invasion assay. The inhibitory effect of EGCG on RCC cells invasion in vitro was assessed using Transwell chambers ( $8 \mu \mathrm{m}$ pore size; EMD Millipore, Billerica, MA, USA) with membranes coated with $100 \mu \mathrm{l}(1 \mathrm{mg} / \mathrm{ml})$ matrigel (BD Biosciences). Cell lines 786-O and ACHN were placed in serum-free-RPMI-1640 medium for $24 \mathrm{~h}$. Following trypsinization (Sigma-Adrich), cells were washed with PBS and resuspended in serum-free medium. Subsequently, cell suspensions $\left(2 \times 10^{5}\right.$ cells $\left./ \mathrm{ml}\right)$ were added to the upper chambers containing EGCG dissolved in the medium at various concentrations, and RPMI-1640 containing 10\% FBS was placed in the lower chambers. Following incubation for $24 \mathrm{~h}$ in a humidified atmosphere containing $5 \% \mathrm{CO}_{2}$ at $37^{\circ} \mathrm{C}$, non-invasive cells on the upper surface were removed with a cotton swab. The invasive cells on the lower chamber were fixed with $75 \%$ ethanol and then stained with $0.5 \%$ crystal violet (Beijing Chemical Works, Beijing, China). For each membrane, images of three different fields were captured. Results are presented as images of invading cells. All experiments were performed in triplicate.

Gelatin zymography. The activity of MMP-2 and MMP-9 treated with various concentrations of EGCG was evaluated using gelatin zymography. Briefly, following treatment with EGCG in serum-free RPMI-1640 medium for $24 \mathrm{~h}$, the conditioned medium was obtained and the supernatant collected by centrifugation at $4^{\circ} \mathrm{C}$ and $447.2 \mathrm{x} \mathrm{g}$ for $10 \mathrm{~min}$. The samples were loaded and separated by electrophoresis on $10 \%$ sodium dodecyl sulfate (SDS)-polyacrylamide gel electrophoresis (Sigma-Aldrich) with $1 \mathrm{mg} / \mathrm{ml}$ gelatin at $100 \mathrm{~V}$ for $2 \mathrm{~h}$ at $4^{\circ} \mathrm{C}$. Following this, the gels were washed twice in 2.5\% Triton X-100 (Sigma-Aldrich) for $30 \mathrm{~min}$ at room temperature to remove SDS, and incubated overnight in zymography developing buffer containing $50 \mathrm{mM}$ Tris- $\mathrm{HCl}$ and $10 \mathrm{mM} \mathrm{CaCl}_{2}\left(\mathrm{pH} 7.5\right.$; Sigma-Aldrich) at $37^{\circ} \mathrm{C}$. Subsequent to incubation, gels were stained with $0.5 \%$ Coomassie Blue for $30 \mathrm{~min}$ at room temperature and stained with $30 \%$ methanol and 10\% glacial acetic acid (all Beijing Chemical Works, Beijing, China). The gelatinase activity of MMP-2 and MMP-9 was visualized as clear bands against the dark blue background, and band density was measured using Quantity One 4.6.3 software (Bio-Rad Laboratories, Inc.). Results were expressed by the percentage of the density to the control bands. A minimum of three independent experiments were conducted with individual protein samples.

Western blot analysis. Western blotting was performed to determine the protein expression levels of MMP-2 and MMP-9. Following treatment with EGCG for $24 \mathrm{~h}$, cell lines 786-O and 
<smiles>O=C(O[C@H]1Cc2c(O)cc(O)cc2O[C@@H]1c1cc(O)c(O)c(O)c1)c1cc(O)c(O)c(O)c1</smiles>

B

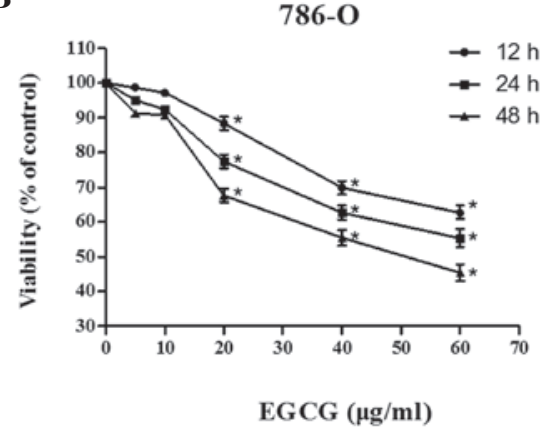

C

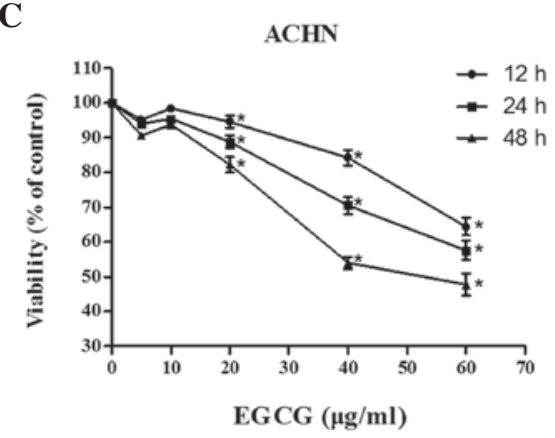

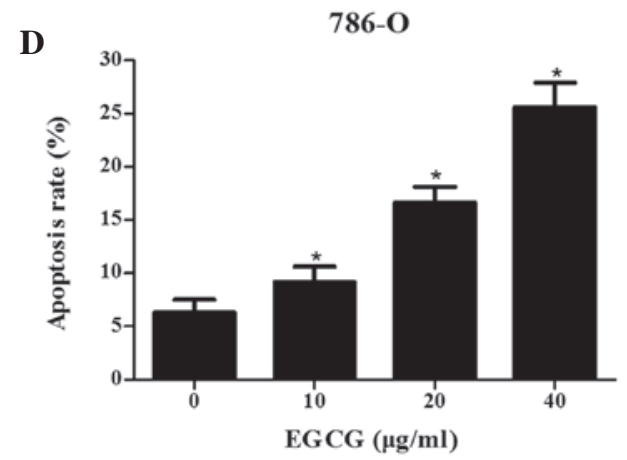

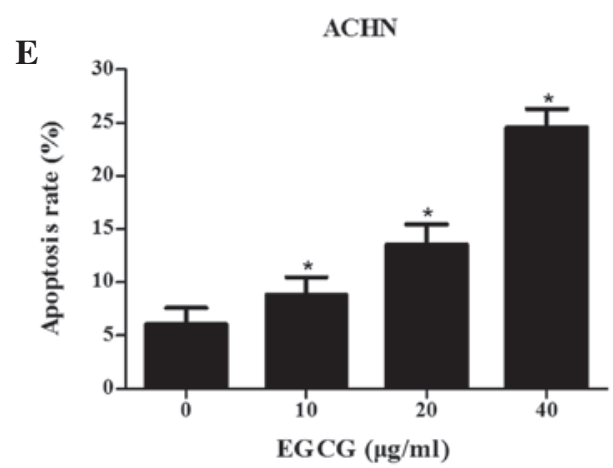

Figure 1. Effect of EGCG on the proliferation and apoptosis of renal cell carcinoma cells. (A) Chemical structure of EGCG. (B) Effect of EGCG on 786-O cell viability at various concentrations. (C) Effect of EGCG on ACHN cell viability at various concentrations. (D) Percentage of early and late apoptotic 786-O cells. (E) Percentage of early and late apoptotic ACHN cells. An MTT assay demonstrated a dose- and time-dependent anti-proliferative effect of EGCG on 786-O and ACHN cells. Flow cytometry data indicated a higher apoptotic rate in EGCG treatment groups for 786-O and ACHN cell lines vs. control groups. Data are presented as the mean \pm standard error of the mean of 3 independent experiments. Statistically significant differences are indicated as " $\mathrm{P}<0.05$. EGCG, epigallocatechin-3-gallate.

ACHN were harvested and lysed in radioimmunoprecipitation assay buffer $(50 \mathrm{mM}$ Tris/ $\mathrm{HCl}, \mathrm{pH} 7.4 ; 150 \mathrm{mM} \mathrm{NaCl} ; 1 \%$ NP-40; $0.1 \%$ SDS) containing a protease inhibitor cocktail (both Sigma-Aldrich) for $30 \mathrm{~min}$ on ice. Following this, the lysates were collected and centrifuged for $20 \mathrm{~min}$ at $25,155 \mathrm{x} \mathrm{g}$ at $4^{\circ} \mathrm{C}$. Protein concentration was evaluated with the Protein Quantification Assay kit (K3000-BCA; Shanghai Shenergy Biocolor BioScience \& Technology Co., Ltd., Shanghai, China). Proteins (50 $\mu \mathrm{g})$ were separated on $10 \%$ SDS gels and transferred onto polyvinylidene fluoride membranes (GE Healthcare, Chalfont, UK). The membranes were blocked with $5 \%$ skimmed milk on a shaking table for $2 \mathrm{~h}$, washed three times with PBS for $5 \mathrm{~min}$ and incubated with the following primary mouse anti-human monoclonal immunoglobulin $\mathrm{G}_{1}$ antibodies: Anti-MMP-2 (sc-53630), anti-MMP-9 (sc-13520) and anti- $\beta$-actin (sc-130301; all 1:600; all Santa Cruz Biotechnology, Inc., Dallas, TX, USA) overnight at $4^{\circ} \mathrm{C}$. Following washing three times with PBS with Tween 20 on a shaking table for $5 \mathrm{~min}$, membranes were incubated with secondary goat anti-mouse antibodies (sc-395763; 1:300; Santa Cruz Biotechnology, Inc.) for $2 \mathrm{~h}$ at room temperature. Finally, blots were scanned with red and green light at intensities of 3.5 and 8.0, respectively, to reveal the expression levels of MMP-2 and MMP-9. Protein quantification was conducted with BCA working media (Sigma-Aldrich). Protein expression levels were normalized against those of $\beta$-actin. All experiments were conducted in triplicate.
Statistical analysis. All values are expressed as the mean \pm standard error of the mean. Each value is the mean of at least three separate experiments in each group. Data from in vitro experiments between the treatment groups were analyzed using one-way analysis of variance. A paired Student's t test was performed to analyze the results for statistical significance, when only two conditions were compared. $\mathrm{P}<0.05$ was considered to indicate a statistically significant difference.

\section{Results}

EGCG inhibits proliferation and induces apoptosis in RCC cells. An MTT assay was performed to evaluate the effect of EGCG on the viability of RCC cells. EGCG treatment at various concentrations $(0,5,10,20,40$ and $60 \mu \mathrm{g} / \mathrm{ml})$ resulted in dose- and time-dependent anti-proliferative effect on 786-O and ACHN cell lines (Fig. 1B and C). EGCG-induced apoptosis was then measured using flow cytometry. The data reveals higher apoptosis rates in EGCG treatment groups compared with the control group (Fig. 1D and E). The aforementioned results demonstrated that EGCG was able to significantly inhibit the proliferation of RCC cells by inducing apoptosis $(\mathrm{P}<0.05)$.

EGCG inhibits the migration and invasion of RCC cells. The effect of EGCG on RCC cells migration and invasion was evaluated using wound-healing and Transwell invasion assays, respectively. The present results indicate that EGCG 

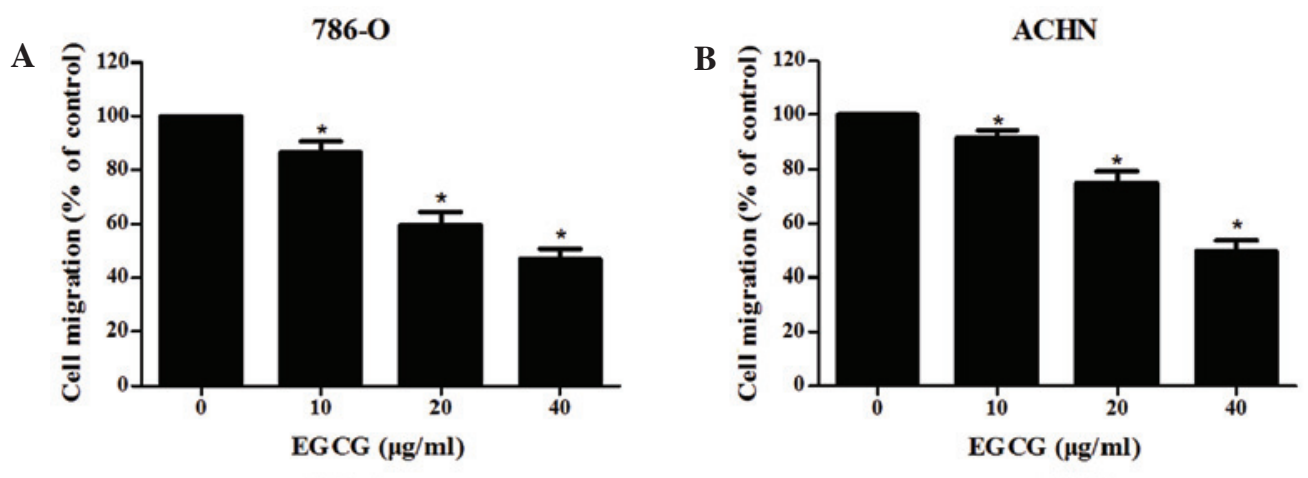

$786-\mathrm{O}$
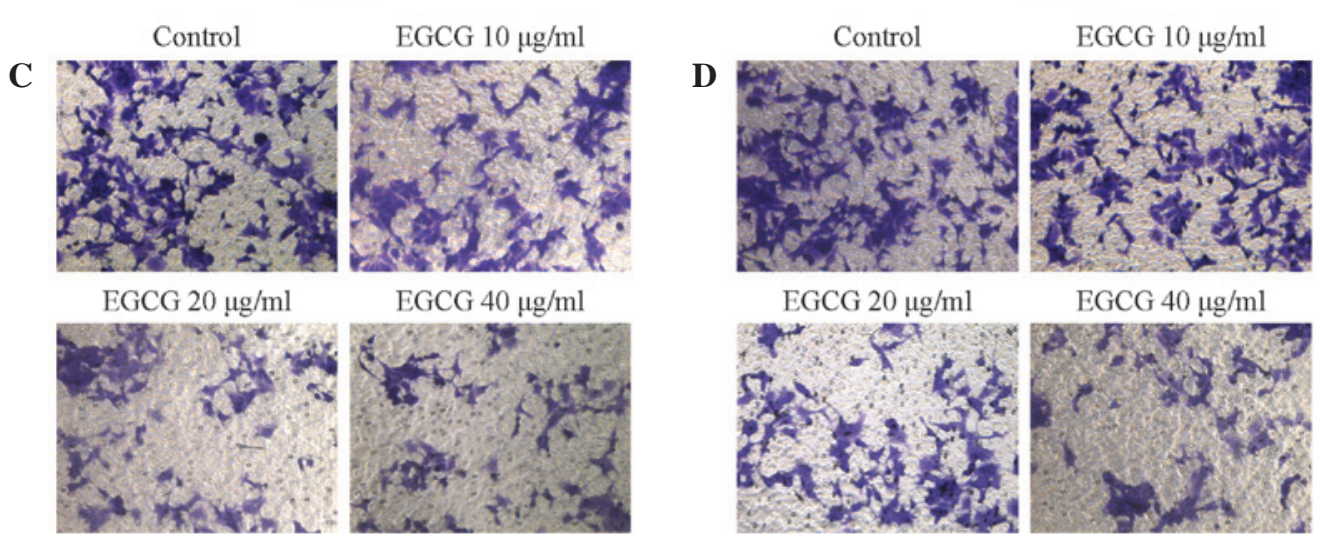

Figure 2. Effect of EGCG on the migration and invasion of renal cell carcinoma cells in vitro. (A) Quantification of 786-O cell migration across the line after treatment with EGCG for $24 \mathrm{~h}$; bars represent percentage of cells migrating vs. control group. (B) Quantification of ACHN cell migration across the wound border after treatment with EGCG for $24 \mathrm{~h}$; bars represent percentage of cells migrating vs. control group. (C) Images of the invasion of 786-O cells through the matrigel-coated polycarbonate membrane. (D) Images indicating the invasion of ACHN cells through the matrigel-coated polycarbonate membrane. Magnification, 100x. The results indicated that EGCG was able to effectively suppress the migration and invasion of RCC cells. Data are presented as mean \pm standard error of the mean of three independent experiments. Statistically significant differences are indicated as " $\mathrm{P}<0.05$. EGCG, epigallocatechin-3-gallate.

A

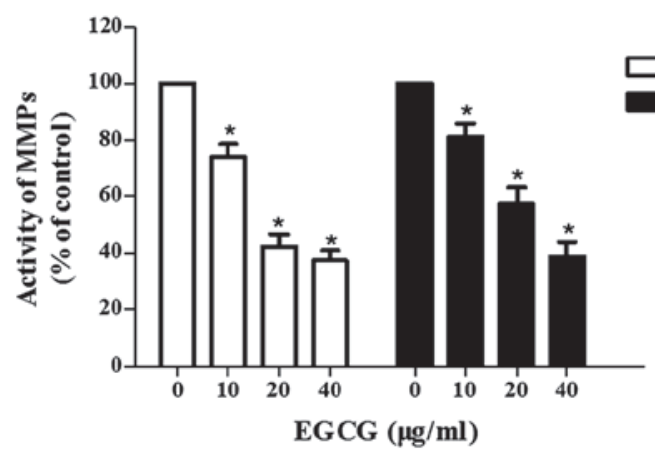

C

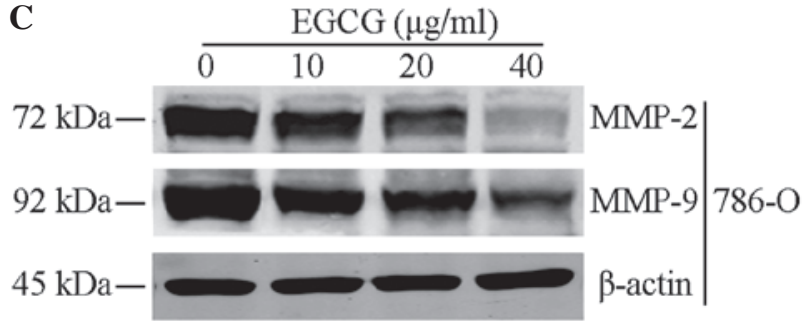

$\mathbf{B}$

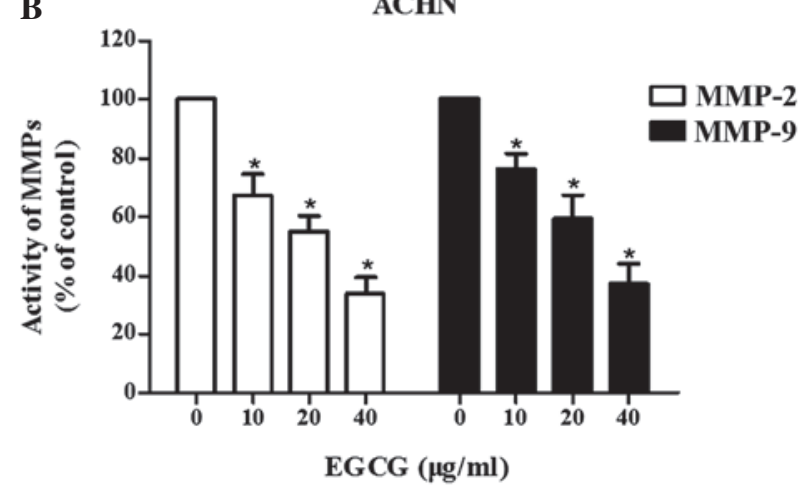

D

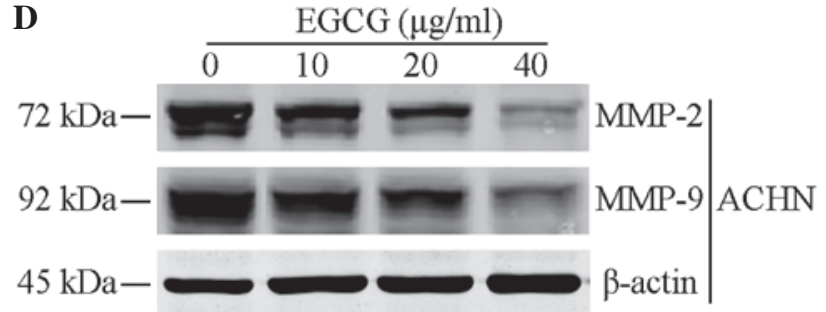

Figure 3. Effect of EGCG on MMP-2 and MMP-9 activity and expression levels in renal cell carcinoma cells. (A) Quantification of gelatin zymography data for MMP-2 and MMP-9 in 786-O cells. (B) Quantification of gelatin zymography data for MMP-2 and MMP-9 in ACHN cells. The bars represent the ratios of activity in EGCG treatment groups vs. control group. (C) MMP-2 and MMP-9 expression detected by western blotting after treatment with EGCG for $24 \mathrm{~h}$ in 786-O cells. (D) MMP-2 and MMP-9 expression detected by western blotting after treatment with EGCG for $24 \mathrm{~h}$ in ACHN cells. Gelatin zymography data revealed that EGCG significantly suppressed MMP-2 and MMP-9 activity in 786-O and ACHN cells. Western blotting indicated that EGCG markedly reduced MMP-2 and MMP-9 expression levels in 786-O and ACHN cell lines. Data are presented as mean \pm standard error of the mean for a minimum of three independent experiments. Statistically significant changes at * $\mathrm{P}<0.05$. EGCG, epigallocatechin-3-gallate; MMP, matrix metalloproteinase. 
is able to effectively suppress the migration of RCC cells (Fig. 2A and B), and the inhibitory effect of EGCG on RCC cell invasion was also indicated (Fig. 2C and D).

EGCG downregulates MMP-2 and MMP-9 activity and expression levels in RCC cells. Gelatin zymography and western blot analysis were performed to analyze the effect of EGCG on the activity and protein expression levels of MMP-2 and MMP-9 following treatment with EGCG. Results indicated that EGCG significantly reduced the activity and expression of MMP-2 and MMP-9 (P<0.05; Fig. 3). The present results suggested that decreasing MMP-2 and MMP-9 activity and expression levels may be a mechanism by which EGCG's exerts its anti-cancer effects on RCC cell lines.

\section{Discussion}

RCC is the most commonly observed carcinoma in adults and its incidence has gradually increased in the last two decades (17). RCC is the third most common urological cancer and also has the highest mortality rate (18). Metastasis is the greatest challenge in the clinical management of patients with RCC (19) with approximately one third of patients eventually developing metastases, predominately to bone, lung and brain (20), despite having previously undergone a successful nephrectomy. Previous studies revealed that MMP-2 and MMP-9 are associated with metastatic and invasive behavior in a number of cancer types $(21,22)$. Therefore, MMP-2 and MMP-9 are potential targets for the treatment of RCC, and novel agents or phytochemical compounds are attracting increasing attention.

Natural plant extracts have historically been regarded as potential therapeutic agents and several plant extracts have demonstrated anticancer effects. Ma et al demonstrated that curcumin was able to inhibit pancreatic cancer cell growth and invasion through upregulation of miR-7 (23), whilst Lee et al (24) demonstrated the anti-metastatic effect of resveratrol against 4T1 mouse breast cancer cells by decreasing MMP-9 activity. Furthermore, Kim et al (25) reported that quercetin was able to induce apoptosis in HT-29 colon cancer cells via the adenosine monophosphate-activated protein kinase signaling pathway. In recent years plant polyphenols, in particular EGCG (the major catechin found in green tea), have received increased attention. The anticancer effects of EGCG have been investigated in several in vitro studies. Luo et al (26) reported that EGCG inhibited the cell growth and proliferation of MCF-7 breast cancer cells by downregulating hypoxia-inducible factor- $1 \alpha$ and vascular endothelial growth factor protein expression levels. Sakamoto et al (27) revealed that EGCG suppresses the proliferation and angiogenesis in lung cancer A549 cells and Lee et al (28) reported that EGCG induces human laryngeal epidermoid carcinoma Hep2 cell apoptosis by upregulating apoptosis-inducing factor and endonuclease G. However, the effects of EGCG on RCC cells have yet to be elucidated.

In the present study, it was initially demonstrated that EGCG effectively inhibits the migration and invasion of human RCC cells by downregulating MMP-2 and MMP-9. As demonstrated by MTT assay and flow cytometry, EGCG was able to inhibit proliferation and promote apoptosis of
RCC cells in a dose- and time-dependent manner. In addition, wound-healing assays revealed that EGCG markedly decreases RCC cell migration and a Transwell invasion assessment indicated that EGCG significantly reduces the invasion ability of RCC cells. As MMP-2 and MMP-9 have previously been demonstrated to promote invasion and metastasis in malignant tumors $(29,30)$, we hypothesized that EGCG would inhibit the migration and invasion of RCC cells by downregulating MMP-2 and MMP-9 expression levels. Gelatin zymography and western blot analysis were performed, respectively. As hypothesized, EGCG decreased MMP-2 and MMP-9 activity in RCC cells and MMP-2 and MMP-9 expression levels subsequent to EGCG treatment was strongly suppressed. Thus, the present results suggest that EGCG is able to inhibit the proliferation, migration and invasion of RCC cells and the underlying mechanisms are associated with the suppression of the activity and expression levels of MMP-2 and MMP-9.

The present study did not; however, determine how EGCG impacts the activity and expression levels of MMP-2 and MMP-9 in RCC cells. As previously reported in the literature, EGCG was able to induce G2/M arrest in CL1-5 lung cancer cells via c-Jun N-terminal kinase JNK signaling (31). In addition, ECGG was able to regulate the focal adhesion kinase/extracellular regulated kinase/nuclear factor- $\kappa \mathrm{B}$ and activator protein (AP)-1 axis in a human breast cancer cell line (32). Furthermore, EGCG was able to suppress mitogen-activated protein kinase and AP-1 activation in human gastric AGS cells (33). Future studies are required to elucidate the underlying process and mechanism regarding the effects of EGCG on MMP-2 and MMP-9.

In conclusion, the present study proposed that EGCG would exert anticancer effects on RCC cells and the present findings demonstrated that EGCG was able to inhibit the migration and invasion of RCC cells by downregulating MMP-2 and MMP-9, which suggested EGCG may be a potential therapeutic or adjuvant strategy for the treatment of patients with RCC. However, clinical trials are required in the future to determine safety and efficacy.

\section{Acknowledgements}

The present study was partially supported by grants from the National Natural Science Foundation of China (grant nos. 81000311 and 81270831 ).

\section{References}

1. Xue YJ, Xiao RH, Long DZ, Zou XF, Wang XN, Zhang GX, Yuan YH, Wu GQ, Yang J, Wu YT, et al: Overexpression of FoxM1 is associated with tumor progression in patients with clear cell renal cell carcinoma. J Transl Med 10: 200, 2012

2. Mancuso A and Sternberg CN: New treatments for metastatic kidney cancer. Can J Urol 12 (Suppl 1): S66-S70; discussion 105, 2005.

3. Zisman A, Pantuck AJ, Wieder J, Chao DH, Dorey F, Said JW, deKernion JB, Figlin RA and Belldegrun AS: Risk group assessment and clinical outcome algorithm to predict the natural history of patients with surgically resected renal cell carcinoma. J Clin Oncol 20: 4559-4566, 2002.

4. Cohen HT and McGovern FJ: Renal-cell carcinoma. N Engl J Med 353: 2477-2490, 2005.

5. Chambers AF, MacDonald IC, Schmidt EE, Morris VL and Groom AC: Clinical targets for anti-metastasis therapy. Adv Cancer Res 79: 91-121, 2000. 
6. Bracken CP, Gregory PA, Khew-Goodall Y and Goodall GJ: The role of microRNAs in metastasis and epithelial-mesenchymal transition. Cell Mol Life Sci 66: 1682-1699, 2009.

7. Cakarovski K, Leung JY, Restall C, Carin-Carlson A, Yang E, Perlmutter P, Anderson R, Medcalf R and Dear AE: Nove inhibitors of urokinase-type plasminogen activator and matrix metalloproteinase expression in metastatic cancer cell lines. Int J Cancer 110: 610-616, 2004.

8. Toda D, Ota T, Tsukuda K, Watanabe K, Fujiyama T, Murakami M, Naito M and Shimizu N: Gefitinib decreases the synthesis of matrix metalloproteinase and the adhesion to extracellular matrix proteins of colon cancer cells. Anticancer Res 26: 129-134, 2006.

9. Nelson AR, Fingleton B, Rothenberg ML and Matrisian LM: Matrix metalloproteinases: Biologic activity and clinical implications. J Clin Oncol 18: 1135-1149, 2000.

10. Stoner GD and Mukhtar H: Polyphenols as cancer chemopreventive agents. J Cell Biochem Suppl 22: 169-180, 1995.

11. Katiyar S and Mukhtar H: Tea in chemoprevention of cancer. Int J Oncol 8: 221-238, 1996.

12. Chen D, Wan SB, Yang H, Yuan J, Chan TH and Dou QP: EGCG, green tea polyphenols and their synthetic analogs and prodrugs for human cancer prevention and treatment. Adv Clin Chem 53: 155-177, 2011

13. Roomi MW, Monterrey JC, Kalinovsky T, Rath $M$ and Niedzwiecki A: Comparative effects of EGCG, green tea and a nutrient mixture on the patterns of MMP-2 and MMP-9 expression in cancer cell lines. Oncol Rep 24: 747-757, 2010.

14. Lim YC, Park HY, Hwang HS, Kang SU, Pyun JH, Lee MH, Choi EC and Kim CH: (-)-Epigallocatechin-3-gallate (EGCG) inhibits HGF-induced invasion and metastasisin hypopharyngeal carcinoma cells. Cancer Lett 271: 140-152, 2008.

15. Siddiqui IA, Malik A, Adhami VM, Asim M, Hafeez BB, Sarfaraz S and Mukhtar H: Green tea polyphenol EGCG sensitizes human prostate carcinoma LNCaP cells to TRAIL-mediated apoptosis and synergistically inhibits biomarkers associated with angiogenesis and metastasis. Oncogene 27: 2055-2063, 2008.

16. Shankar S, Ganapathy S, Hingorani SR and Srivastava RK: EGCG inhibits growth, invasion, angiogenesis and metastasis of pancreatic cancer. Front Biosci 13: 440-452, 2008.

17. Volpe A and Patard JJ: Prognostic factors in renal cell carcinoma. World J Urol 28: 319-327, 2010.

18. Qiao HP, Gao WS, Huo JX and Yang ZS: Long non-coding RNA GAS5 functions as a tumor suppressor in renal cell carcinoma. Asian Pac J Cancer Prev 14: 1077-1082, 2013.

19. Zhang L, Xul B, Chen S, Lu K, Liu C, Wang Y, Zhao Y, Zhang X, Liu D and Chen M: The complex roles of microRNAs in the metastasis of renal cell carcinoma. J Nanosci Nanotechnol 13 3195-3203, 2013

20. Janzen NK, Kim HL, Figlin RA and Belldegrun AS: Surveillance after radical or partial nephrectomy for localized renal cell carcinoma and management of recurrent disease. Urol Clin North Am 30: 843-852, 2003.
21. Waas ET, Wobbes T, Lomme RM, DeGroot J, Ruers T and Hendriks T: Matrix metalloproteinase 2 and 9 activity in patients with colorectal cancer liver metastasis. Br J Surg 90: 1556-1564, 2003.

22. Zhang L, Shi J, Feng J, Klocker H, Lee C and Zhang J: Type IV collagenase (matrix metalloproteinase-2 and -9) in prostate cancer. Prostate Cancer Prostatic Dis 7: 327-332, 2004.

23. Ma J, Fang B, Zeng F, Pang H, Zhang J, Shi Y, Wu X, Cheng L, Ma C, Xia J and Wang Z: Curcumin inhibits cell growth and invasion through up-regulation of miR-7 in pancreatic cancer cells. Toxicol Lett 231: 82-91, 2014.

24. Lee HS, Ha AW and Kim WK: Effect of resveratrol on the metastasis of 4T1 mouse reast cancer cells in vitro and in vivo. Nutr Res Pract 6: 294-300, 2012.

25. Kim HJ, Kim SK, Kim BS, Lee SH, Park YS, Park BK, Kim SJ, Kim J, Choi C and Kim JS: Apoptotic effect of quercetin on HT-29 colon cancer cells via the AMPK signaling pathway. J Agric Food Chem 58: 8643-8650, 2010.

26. Luo HQ, Xu M, Zhong WT, Cui ZY, Liu FM, Zhou KY and Li XY: EGCG decreases the expression of HIF-1 $\alpha$ and VEGF and cell growth in MCF-7 breast cancer cells. J BUON 19: 435-439, 2014.

27. Sakamoto Y, Terashita N, Muraguchi T, Fukusato T and Kubota S: Effects of epigallocatechin-3-gallate (EGCG) on A549 lung cancer tumor growth and angiogenesis. Biosci Biotechnol Biochem 77: 1799-1803, 2013.

28. Lee JH, Jeong YJ, Lee SW, Kim D, Oh SJ, Lim HS, Oh HK, Kim SH, Kim WJ and Jung JY: EGCG induces apoptosis in human laryngeal epidermoid carcinoma Hep2 cells via mitochondria with the release of apoptosis-inducing factor and endonuclease G. Cancer Lett 290: 68-75, 2010.

29. Chambers AF and Matrisian LM: Changing views on the role of matrix metalloprotenases in metastasis. J Natl Cancer Inst 89: 1260-1270, 1997.

30. Kleiner DE and Stetler-Stevenson WG: Matrix metalloproteinases and metastasis. Cancer Chemother Pharmacol 43 (Suppl): S42-S51, 1999.

31. Deng YT and Lin JK: EGCG inhibits the invasion of highly invasive CL1-5 lung cancer cells through suppressing MMP-2 expression via JNK signaling and induces $\mathrm{G} 2 / \mathrm{M}$ arrest. J Agric Food Chem 59: 13318-13327, 2011.

32. Sen T, Dutta A and Chatterjee A: Epigallocatechin-3-gallate (EGCG) downregulates gelatinase-B (MMP-9) by involvement of FAK/ERK/NFkappaB and AP-1 in the human breast cancer cell line MDA-MB-231. Anticancer Drugs 21: 632-644, 2010.

33. Kim HS, Kim MH, Jeong M, Hwang YS, Lim SH, Shin BA, Ahn BW and Jung YD: EGCG blocks tumor promoter-induced MMP-9 expression via suppression of MAPK and AP-1 activation in human gastric AGS cells. Anticancer Res 24: $747-753,2004$ 